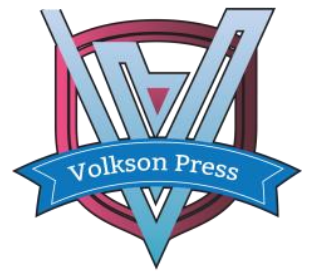

Contents List available at VOLKSON PRESS

Economics \& Management Innovations(EMI)

DOI : http://doi.org/10.26480/icemi.01.2017.389.391

\title{
Discussions on Issues of China's Internet Finance Regulations and Policies
}

\author{
Chao-Feng Hsu 1,2, Jieying $\mathrm{Xu}^{2}$, Bi-Ru Lee ${ }^{2}$
}

1Zhou Enlai School of Government, Nankai University, Tianjin300071, China

2Zhongshan Institute, University of Electronic Science and Technology of China, Guangdong

528402,China

visonhsu8989@126.com, xuujieying@126.com, maggen_lee@hotmail.com

This is an open access article distributed under the Creative Commons Attribution License, which permits unrestricted use, distribution, and reproduction in any medium, provided the original work is properly cited.

\section{ARTICLE DETAILS}

\section{Article History:}

Received 02 october 2017

Accepted 06 october 2017

Available online 11 october 2017

\section{Keywords:}

Internet Finance, Financial

Regulation, Absence of

Regulation, Lack of Policy,

Feasible Solution.

\section{ABSTRACT}

China's Internet finance has, though starting late, gained rapid development recently. Considering the environmental complexity and diversity, the difficulty of financial regulations is higher and the requirements will be stricter than any other country or region. The main cause is that the Internet finance is an emerging industry. In the meantime, the country's Commercial Bank Law, Securities Law and Insurance Law among other laws have not fully covered the range of Internet finance. Moreover, the Bank of China, China Securities Regulatory Commission, China Banking Regulatory Commission and China Insurance Regulatory Commission are respectively in charge of their separate functions, which may lead to the huge vacuum of financial regulation and policy. The above realities require us to ponder, looking for possible alternatives and strategies, and improve the domestic market of Internet finance in a more robust pace and effective construction.

\section{Introduction}

The internet finance hasn't changed the essence of traditional finance. The differences of internet finance primarily lie in its innovation made to the channel, including informatization and transformation to network. The core of Internet spirit is open, equality, cooperation, and sharing. The idea is about breaking the barrier between virtuality and reality, breaking the constraints of time and space, and realizing the maximization of efficiency and effectiveness with the power of the masses. The information technology has enabled financial services to be more effective and convenient and the advantages are as follows ${ }^{1}$ :

(1) Big data technology can provide credit services for small and medium-sized enterprises;

(2) The use of big data can better satisfy customer personalized financing needs;

(3) With the support of big data and cloud computing, the financial costs will be reduced,

The perfect connection of the capital flow of the banks, the information flow of the internet platforms and the commodity flow of small and medium-sized enterprises can solve the problem of information asymmetry and enterprises' credit investigation. Electronic business platforms and banks can carry out deep cooperation to establish exclusive credit database for enterprise financing as a way to reduce financing difficulties of small and medium-sized enterprises ${ }^{2}$. However, due to the huge momentum of Internet finance, the domestic financial ecology and the competition are under significant influence, and many non-compliance financial problems have arisen. Whether strengthened supervision and regulation should be imposed on internet finance, to what extent should they be carried out and how to implement are urgent issues. But the greatest difficulty is the internal contradiction between financial innovation and regulation system.

According to Changkyu Choi, Dong-Eun Rhee, Yonghyup Oh et al..$^{3-6}$, the combination of Internet and financial can promote the development of the real economy mainly by alleviating the information asymmetry problems in reality through the flow of information, which will drive cash flow. Moreover, internet finance can transcend the limit of time and space, promoting cross-border investment. Internet finance also increases the synergy between the flow of information and financing. Last but not least, big data technology can better meet the financial needs and conduct credit investigation for the customers. All of the above are what traditional finance failed to accomplish.

In 2014, the French economist Jean Tirole conducted fundamental study of financial regulation, many accomplishments of which are especially in the prevention of financial shocks. In 1994, he collaborated with Dewatripont in a book called the Prudential Regulation of Banking using the financial contract theory to analyze of solvency requirements and the optimal regulation of asset securitization. They emphasized that the optimal regulation should balance both ex ante and ex post efficiency. In 1997 he and Holmstrom jointly established the analytic model of financial intermediations, proving counter-cyclical capital requirements should be implemented. After the subprime crisis hit the United States, Tirole began to regard the shadow banking as one of the culprits of financial shocks, and focused on the moral hazard of financial institutions, and put forward the concept of macro-prudential regulation. These arguments are can provide us ideas and perspectives for the future financial regulations $\mathrm{s}^{7-8}$.

\section{A Brief Introduction of China's Internet Finance}

At present, both the formal financial institutions and the informal financial institutions have contributed to the diversification of internet finance in China. In essence, however, both types of institutions are taking the advantage of information technology to promote the development of finance, which means internet finance still falls into the category of finance. Conceptually, internet finance includes Internet payment and Internet financing. Under the current circumstances where the industry is enjoying skyrocket growth, risks are occurring frequently, and have seriously interfered with the normal financial order. To make matter worse, the lack of relevant law laws and regulations or deficiency are increasing the seriousness of the problem.In 2011, China Banking Regulatory Commission published "Notice on the Risks of Renrendai", saying that Renrendai, as an intermediary company of credit loan service (P2P lending), had a large number of potential risks and problems. The internet midwifed various P2P lending platforms that drew in great amount of idle fund. In this crazy rush of P2P lending platforms' establishment, it is not difficult to discover the law breakers are conducting illegal fund-raising under the guise of financial innovation. Such illegal behavior is setting the time bombs under the very foundation of the financial institution?. 


\section{The Risk of Internet Finance}

The combination of risky finance and the pervasive internet enables the risk of internet finance to reach much wider and faster than that of traditional finance. From the perspective of risk prevention, it is not only necessary but also profoundly significant to regulate internet activity. In order to conduct macro-prudential regulation on the financial activity, internet, as the popular media of it, constitutes no exception.

In America, for example, regulations cover third-party payment, P2P lending and crowd funding. Functional regulation is implemented on the activity of third-party payment, and the regulatory emphasis is placed on the non-third party institutions ${ }^{10-11}$.

\subsection{The Risks of Internet Finance}

Internet finance is a kind of financial innovation, which implicates that the inherent financial risks haven't been removed. Certain risks and crossover relevance exists in the low coupling between the financial technology and its business. Current the regulatory authorities think that there are three major risks in the internet finance. The first one is the unclear legal position, the second is the lack of capital depository, and the third is the unsound internal control system that leads to operation risk easily.

Besides the inherent financial risk, there are also risks specific to this combination, which are in particular the legal and policy risks. Because of the rapid pace of Internet financial development, current a part of business exists beyond the reach of legal and regulatory system, so the practitioners are lurking in grey zone. Considering peer-to-peer's similar nature with private lending, fraud and loan sharks among other similar risks may be involved. If unattended, the practitioners and the institutions will face serious legal and policy risks.

\subsection{The Internet's Impact on the Financial System}

(1) Traditional financial business has been upgraded by the internet, yet the latter is still a kind of supplement to the former. Take Yu'ebao as an example. Its size of its capital is more than 1 trillion, far exceeding the general financial institutions, whose fund-raising scale has caused obvious impact on the banking institutions.

(2) The third-party payment is not separate from traditional payment and settlement system, but with additional third-party payment platforms among the intermediate links.

(3) Although the internet credit business has multi-level impact, such impact as a whole is still limited.

To a certain extent, the internet finance has overcome the disadvantages of China's lack of financial reform and the existing financial repression. Eventually the internet finance must focus on facilitating real economy, and creating the synergy between online and offline business.

\section{The Regulations on China's Internet Finance and the Problems}

At present, China's rapid development in internet finance is drawing the financial regulatory authorities' attention to the Internet research. The Central Bank has also switched from lassez-faire policy to be in support of regulations. However, consensus must be reached on key issues such as regulatory agencies, regulatory method and regulatory system, etc ${ }^{12-13}$.

\subsection{Regulation Approach:}

4.1.1 Decentralize the regulatory authorities by authorizing the local government fully to supervise under the condition of accepting the Central Bank's supervision and management.

\subsubsection{The principle-based regulation method}

This means that the regulation must not touch upon a few principles, and under these principles, all activities are proper market trading behavior. The principle-based regulation by the local government will be beneficiary for financial innovation without compromising the limit of minimum supervision.

\subsubsection{The safety mechanism of the internet}

(1) Establish the membership mechanism to avoid rules and regulations with non-specificality
(2) Establish the third-party depository mechanism of funds to avoid the risk of fund concentration.

(3) AS far as the internet is concerned, it should play the role of intermediary of information rather than the intermediary of funds whether in the scenario of P2P lending or in crowd funding.

(4) Establish the system of information disclosure to protect the rights and interests of investors

(5) Both peer-to-peer lending and crowd funding fall into the category of direct finance like securities trading. Therefore, it should be obligated to disclose the identifications including the financiers and other information such as use of funds in order to truly protect the rights and interests of investors.

(6) Establish the system of information security to protect the legal rights and interests of investors

(7) Internet finance is emerging financial model with the use of the internet technology and mobile communication technology for the realization of financing and information intermediary. At present, there are three major problems existing. The first one is the influence of internet finance on the traditional financial system. The second is the risks of internet finance, namely the potential systemic risk caused by internet finance. And the third is the regulatory issues, including regulatory scope, regulatory methods and regulatory bodies.

\subsection{Foreign Practical Experience of Internet Finance}

Many foreign scholars have been conducting researches on the relationship between finance and real economic growth, and claiming that there is a positive correlation between financial development and economic growth ${ }^{14-15}$. Europe and the United States among other advanced countries have taken the lead to complete the marketization of interest rate, enabling the capital to flow freely and providing an enormous boost to the real economy. China's financial system is mainly dominated by the banks, who highly concentrate the funds and maintain the monopoly position in a long term. Since the market access has high threshold, the banks enjoy huge policy spreads, making the traditional financial institutions service lag behind the requirements of the social system. It also causes improper allocation of funds. On the one hand, the rate private saving is very high. On the other hand, the real economies of small and medium-sized enterprise are in the predicament of unsatisfied financing needs. Such financial development departs from the free competition of the market, easily causing the low utilization efficiency of social capital ${ }^{16-}$ ${ }^{17}$.In the United States, the services of internet finance are regarded as securities, and placed under regulations similar to the securities. The regulations are being carried out mainly through registration and compulsory information disclosure. The regulatory bodies include Securities and Exchange Commission (SEC), Federal Trade Commission (FTC) and Consumer Financial Protection Bureau (CFPB) and others. In Germany and France, P2P and crowd funding are included by the scope of credit business, and regulated through the licensing. Therefore, foreign regulatory methods are registration, licensing, and mandatory disclosure of information ${ }^{18-20}$.

\subsection{The Existing Problems of China's Internet Finance}

P2P and crowd funding are the important supplementary channels in the real world when sufficient microcredit is not available via traditional banks. In the absence of collateral, personal information becomes the main basis of judgment of the applicants. This requires the big data be used to establish a reliable and open credit database.China's credit system construction is not sound in that there are no just and professional thirdparty rating agencies (e.g. Moody's and Standard \& Poor's) to provide the individuals and the enterprises with complete credit records and professional credit ratings. Therefore, financial institutions find it difficult to accurately investigate the credit status of the small and medium-sized enterprises, giving rise to the financing difficulties of small and mediumsized enterprise and inflating the cost of financing.

\subsection{Challenges for Internet Finance in the Future}

(1) Internet finance is speeding and deepening the trend of financial mixed operation, while the existing financial regulation is based on separate operation mode and relying on regulators. This may lead to the future confusion and mismatch of regulations on separate operation and mixed operation. 
loopholes and gaps may exist.

(3) Issues concerning the internet are demanding proficiency in information and technology. And often interdisciplinary knowledge is needed. Professional obstacles are challenging to the delivery of timely, effective and integrated supervision.

(4) The virtual feature of the internet finance creates the dilemma of obtaining evidence.

\section{Conclusion}

\subsection{Recommendations}

(1) The regulations on internet finance should both encourage its development and strengthen risk prevention. At present, the regulatory authorities are exerting an effective financial regulation, such as including the large scale third-party payment institutions into the regulatory system.

(2) Establish multilevel framework and system of internet governance, from central to local and from single to multiple regulations.

(3) The industry of internet finance should pay attention to its specific risks and the spillover effect of risks in order to avoid regional and systemic risks.

(4) Regulations on internet finance should focus on information security and consumer protection. Mandatory disclosure of information and consumer protection mechanism is one of the most urgent tasks for the financial regulatory authorities.

(5) Comprehensively deepen the reform of the financial market.

\subsection{The Development Strategies}

(1) Establish and improve the system and framework of internet finance. The key to financial service is risk control. It's necessary to set the standard of risk database that is open and compatible.

(2) Establish a sound social credit evaluation system, which is led by the People's Bank of China. PBOC will give mandatory orders to the Banks for establishing database and credit system.

(3) The banks and related internet enterprises and platforms should carry out deep cooperation to achieve effective sharing of the banks' credit data and internet practitioners' trading data. The banks should also develop specific online and offline 020 business channels, where the online businesses are in full range and the offline businesses experience-oriented. The customers' experience can be improved by optimizing the process and the intelligent self-service.

\section{References}

[1] Li, H.C., Tien, Y.H., and Li, W.C., The Internet Thinking and the Reengineering of Traditional Enterprises. China Industrial Economics, 2014, (10).

[2] Cheng, L.C., China's Internet Finance: Model, Influence, Essence and Risks. International Economic Review.

[3] Ho, S.Y., The Correlation Degree between the New Type of Operation "Internet Plus Finance" and the Real Economy Development. Fiscal Levy and Capital Market , 2015(7)

[4] Liu, C.Y., Huang, K.H., Tirole's Theories of Regulations on the Financial Institutions and Thoughts for the Regulations on China's Internet Finance. Comparative Economic \& Social Systems , 2015(3)
[5] Chen, C.Y., Study of Regulations on China's Internet Finance. Master's Thesis of Yunnan University of Finance and Economics (2015).

[6] Li, Y.H., Chen, F., and Chin, Y.F., Discussion and Analysis of Internet Finance. Journal of Zhejiang University, 2014(7).

[7] Lee, Y.C., Chu, W.H., Chen, Q., Tsai, S.B., et al. 2016. Integrating DEMATEL Model and Failure Mode and Effects Analysis to Determine the Priority in Solving Production Problems. Advances in Mechanical Engineering, 8(4), 1-12( 2016).

[8] Tsai, S.B., Xue, Y., Zhang, J., Chen, Q., et al. 2016. Models for Forecasting Growth Trends in Renewable Energy. Renewable \& Sustainable Energy Reviews, 2016, DOI: 10.1016/j.rser.2016.06.001.

[9] Qu, Q., Chen, K.Y., Wei, Y.M., et al. 2015. Using Hybrid Model to Evaluate Performance of Innovation and Technology Professionals in Marine Logistics Industry Mathematical Problems in Engineering, Article ID 361275, 8 pages, http://dx.doi.org/10.1155/2015/361275(2015).

[10] Zhou, J. Wang, Q., Tsai, S.B., et al. 2016. How to Evaluate the Job Satisfaction of Development Personnel. IEEE Transactions On Systems Man Cybernetics-Systems, 10.1109/TSMC.2016.2519860(2016).

[11] Su, J. M., Lee, S. C., Tsai, S. B. \& Lu, T. L. 2016. A comprehensive survey of the relationship between self-efficacy and performance for the governmental auditors. Springer Plus, 5:508. DOI 10.1186/s40064-0162104-x,(2016).

[12] Chen, H.M., Wu, C.H., Tsai, S.B., Yu, J., et al. 2016. Exploring key factors in online shopping with a hybrid model. Springer Plus, 5:2046. DOI 10.1186/s40064-016-3746-4(2016).

[13] Wang, J., Yang, J., Chen Q. \& Tsai, S.B. Collaborative Production Structure of Knowledge-sharing Behavior in Internet Communities. Mobile Information Systems, Article ID 8269474, 9 pages, http://dx.doi.org/10.1155/2016/8269474(2016).

[14] Wang, J., Yang, J., Chen Q. \& Tsai, S.B. Creating the Sustainable Conditions for Knowledge Information Sharing in Virtual Community. Springer Plus, 5:1019, DOI 10.1186/s40064-016-2702-7(2016).

[15] Lee, Y.C., Wang, Y.C., Chien, C.H., Wu, C.H., et al. 2016. Applying Revised Gap Analysis Model in Measuring Hotel Service Quality, Springer Plus, 5:1191, DOI 10.1186/s40064-016-2823-z.

[16] Lee, Y.C., Wang, Y.C., Lu, S.C., Hsieh, Y.F., et al. 2016. An Empirical Research on Customer Satisfaction Study: A Consideration of Different Levels of Performance. Springer Plus, 5:1577, DOI 10.1186/s40064-0163208-z.

[17] Chin, T., Tsai, S.B., Fang, K., Zhu, W., et al. 2016. EO-Performance relationships in Reverse Internationalization by Chinese Global Startup OEMs: Social Networks and Strategic Flexibility. PLoS ONE, 11(9): e0162175, doi:10.1371/journal.pone.0162175.

[18] Lee, S.C., Su, J.M., Tsai, S.B., Lu, T.L., et al. A comprehensive survey of government auditors' self-efficacy and professional Development for improving audit quality. Springer Plus, 5:1263, DOI 10.1186/s40064-0162903-0(2016).

[19] Chen, H.M., Wu, C.H., Tsai, S.B., Yu, J., et al. 2016. Exploring key factors in online shopping with a hybrid model. Springer Plus, 5:2046, DOI 10.1186/s40064-016-3746-4.

[20] Ge, B., Jiang, D., Gao, Y., \& Tsai, S.B. 2016. The Influence of Legitimacy on a Proactive Green Orientation and Green Performance: A Study Based on Transitional Economy Scenarios in China. Sustainability, 8, 1344, 1-20. doi:10.3390/su8121344. 